\title{
Expression analysis of centrin gene in promastigote and amastigote forms of leishmania infantum iranian isolates: a promising target for live attenuated vaccine development against canine leishmaniasis
}

Mohammad Javad Abbaszadeh Afshar ${ }^{1}$, Samira Elikaee ${ }^{1,2}$, Reza Saberi $^{3}$, Sina Mohtasebi ${ }^{1}$ and Mehdi Mohebali ${ }^{1,4^{*}}$

\begin{abstract}
Background: Leishmania parasites express various essential proteins in different growth phases (logarithmic/ stationary) and forms (promastigote/amastigote). Targeting the genes encoding such proteins paves the way for controlling these parasites. Centrin is an essential gene, which its protein product seems to be vital for the proliferation of Leishmania parasites. Herein, this study was contrived to analyze the expression level of the centrin gene in different growth phases and forms of Leishmania infantum (L. infantum) parasites isolated from various endemic areas of canine leishmaniasis (CanL) in Iran.

Results: All three collected isolates were identified as $L$. infantum using polymerase chain reaction-restriction fragment length polymorphism (PCR-RFLP). Real-time reverse transcription (RT)-PCR revealed a statistically significant up-regulation (3.13-fold) in the logarithmic phase promastigotes compared to stationary ones $(p<0.01$ ), whereas centrin was expressed equally in intracellular amastigotes at different time points during cell culture. Also, our finding revealed a slight up-regulation of the centrin gene (1.22-fold) in the intracellular amastigotes compared to logarithmic phase promastigotes, which was found statistically non-significant $(p>0.05)$.

Conclusions: Centrin gene in Iranian isolates of $L$. infantum is more expressed in exponential than stationary phases and seems to be considered as a promising target in the development of a genetically modified live attenuated vaccine for CanL control.
\end{abstract}

Keywords: Centrin gene, Leishmania infantum, Canine leishmaniasis, Gene expression, Real-time RT-PCR

\footnotetext{
* Correspondence: mohebali@tums.ac.ir

'Department of Medical Parasitology and Mycology, School of Public Health, Tehran University of Medical Sciences, Tehran, Iran

${ }^{4}$ Center for Research of Endemic Parasites of Iran (CREPI), Tehran University of Medical Sciences, Tehran, Iran

Full list of author information is available at the end of the article
} 


\section{Background}

Canine leishmaniasis (CanL) caused by Leishmania infantum (L. infantum), as a challenging global zoonosis, is endemic in some areas in Iran and 70 countries around the world [1-3]. The parasite is transmitted accidentally from the infected dogs, as the main reservoir of CanL, to humans through sandflies biting and cause visceral leishmaniasis (VL), the most severe clinical form of leishmaniases. However, the number of new symptomatic human VL cases reported annually is around 100 cases in Iran, reviewing the conducted studies on domestic dogs indicates the disease is prevalent at least in half of the country's provinces $[4,5]$. Therefore the formation of the new VL foci is not far-fetched in Iran.

Vaccination is the most cost-effective control strategy for controlling CanL, in that successful immunization of dogs could interrupt transmission and reduce the incidence of VL significantly [6]. Several approaches for vaccine development against CanL have been evaluated such as killed parasites, live attenuated parasites, recombinant proteins, and naked DNA [6]. Unlike other approaches, live attenuated vaccines lead to interactions with the host immune system resulting in a wide range of antigens similar to natural parasite infection, hence could provide more protection [7]. Development of live attenuated Leishmania parasites, including long-term in vitro cultures, chemical mutagenesis, and irradiation, is associated with some problems like undefined random genetic mutations or potential reversion virulence. While, genetically modified live attenuated vaccines, through targeting the genes encoding essential proteins like growth-regulating or virulence genes, are safe [8]. To target such genes, it would be essential to analyze their function in different forms and growing phases of Leishmania parasites.

Various qualitative and quantitative biochemical parameters affect the differentiation, proliferation, pathogenesis, and survival of Leishmania parasites, which are different in each form and growing phase of the parasite [9-11]. For instance, the genes related to infectivity are up-regulated in metacyclic promastigotes [11]. Amastigotes also change their gene expression levels to survive and multiply in the hostile environment inside the macrophage's phagolysosomes. Some of these modifications in gene expression levels may point to unique parasite genes that could be targeted to the development of a prophylactic vaccine $[12,13]$.

Several studies have characterized genes that may have an essential role in the growth and proliferation of the Leishmania parasite $[10,14]$. Centrin gene and its function concerning the Leishmania parasite proliferation have been described as one of the mentioned genes [15]. Centrin gene product is one of the several regulatory proteins required for duplication or segregation of the centrosome in higher eukaryotes and basal bodies in lower eukaryotes [16]. The role of centrin in cytokinesis of yeast and HeLa cells and also the formation of flagellate in Chlamydomonas has been documented in several studies [17-20]. Also, centrin is described as one of the essential factors in cell division of several protozoa such as Leishmania, Trypanosoma, and Plasmodium [15, 21, 22].

To target centrin for developing a genetically modified live attenuated vaccine against CanL in Iran, it would be essential to analyze its expression in the different forms and growing phases of L. infantum parasites. Hence, this study aimed to compare the expression level of the centrin gene in the logarithmic phase compared to the stationary phase of L. infantum promastigotes and also the comparison of the expression level of the centrin gene in the promastigote and amastigote forms of L. infantum Iranian isolates using real-time reverse transcription (RT)-PCR.

\section{Results}

\section{Molecular characterization}

All three Leishmania isolates collected from various endemic areas of Iran were identified as L. infantum using polymerase chain reaction-restriction fragment length polymorphism (PCR-RFLP). Following the Nacetylglucosamine-1-phosphate transferase (NAGT) gene digestion with the Acetyl-coenzyme A carboxylase 1 (Acc1) enzyme, all isolates exhibited three bands (780, 500 , and $180 \mathrm{bp}$ ) on the agarose gel, which corresponds to L. infantum (Fig. 1).

\section{Complementary DNA (cDNA) synthesis and real-time RT- PCR analysis}

The integrity of synthesized cDNA was determined by conventional PCR through $\alpha$-tubulin amplification as a housekeeping gene. Real-time RT-PCR was used to compare the relative expression of the centrin gene in the logarithmic and stationary phase promastigotes and also in the logarithmic promastigote and amastigote forms of L. infantum isolates. Figure 2 shows significant upregulation of the centrin gene in the logarithmic phase compared to stationary phase $L$. infantum promastigotes in all three collected isolates. The overall average mRNA expression of the centrin gene in the logarithmic phase promastigotes was 3.13-fold of its expression in stationary phase ones $(p<0.01)$.

The results of the current study also showed centrin expressed equally in the intracellular amastigotes at different time points ( $24 \mathrm{~h}$ and $72 \mathrm{~h}$ post-infection) during the cell culture (data not shown). Also, our results revealed a slight up-regulation of the centrin gene (1.22fold) in the intracellular amastigotes compared to logarithmic phase promastigotes, which was found statistically non-significant $(p>0.05)$ (Fig. 3). Moreover, we 


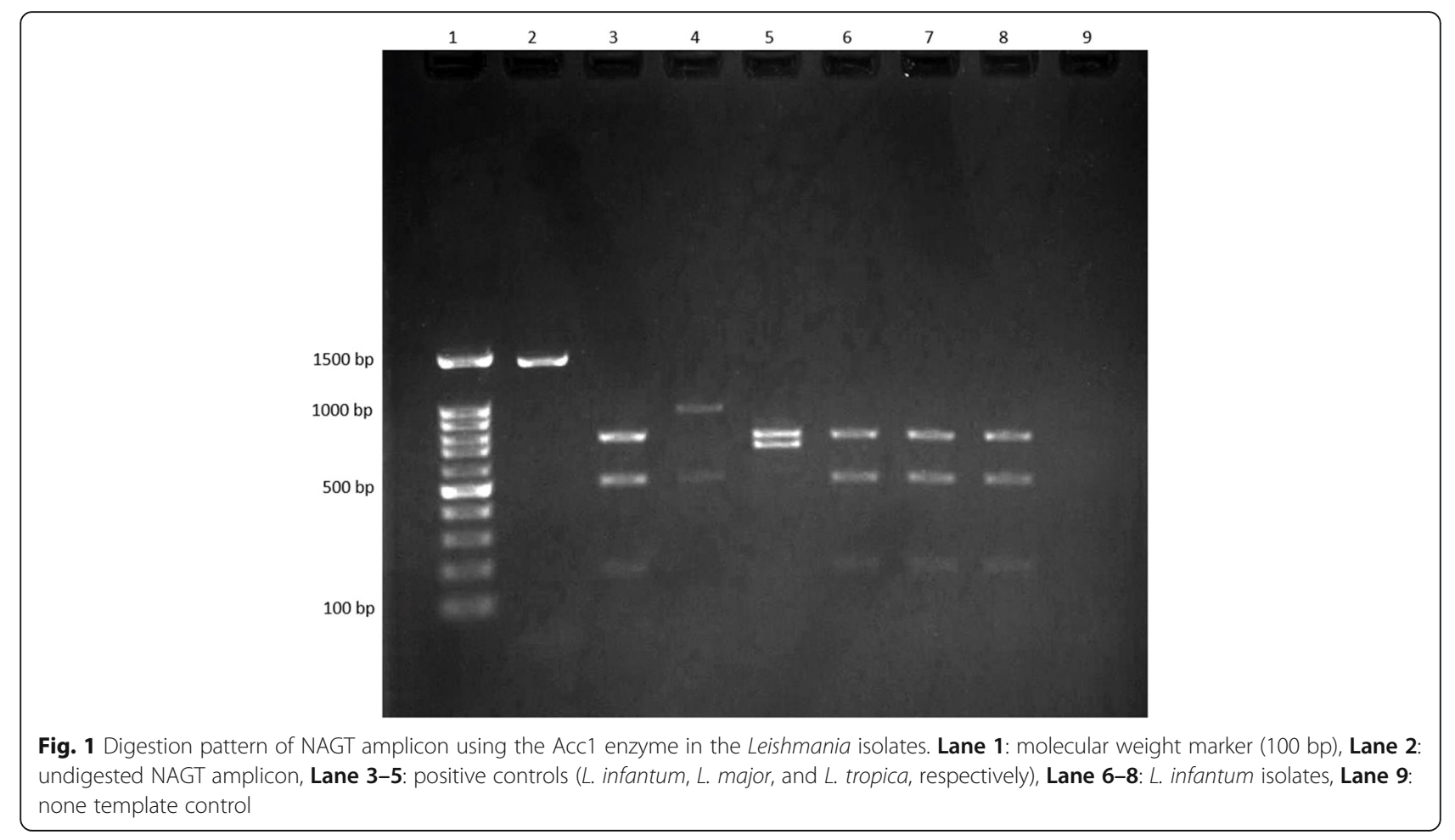

investigated the centrin gene expression level among each $L$. infantum isolate, in which there was no significant difference $(p>0.05)$.

\section{Discussion}

Centrin gene product is a cytoskeletal, calcium-binding protein located at the basal body region of Leishmania parasites. The nature of the basal body and the genes associated with this vital unit in Leishmania parasites are still poorly known. Centrin protein, besides calmodulin, $\gamma$ tubulin, and other types of centrin, is an essential regulatory protein required for duplicating the basal body in Leishmania parasites [15]. To investigate the expression pattern of the centrin gene in different growth phases (logarithmic/stationary) and forms (promastigote/

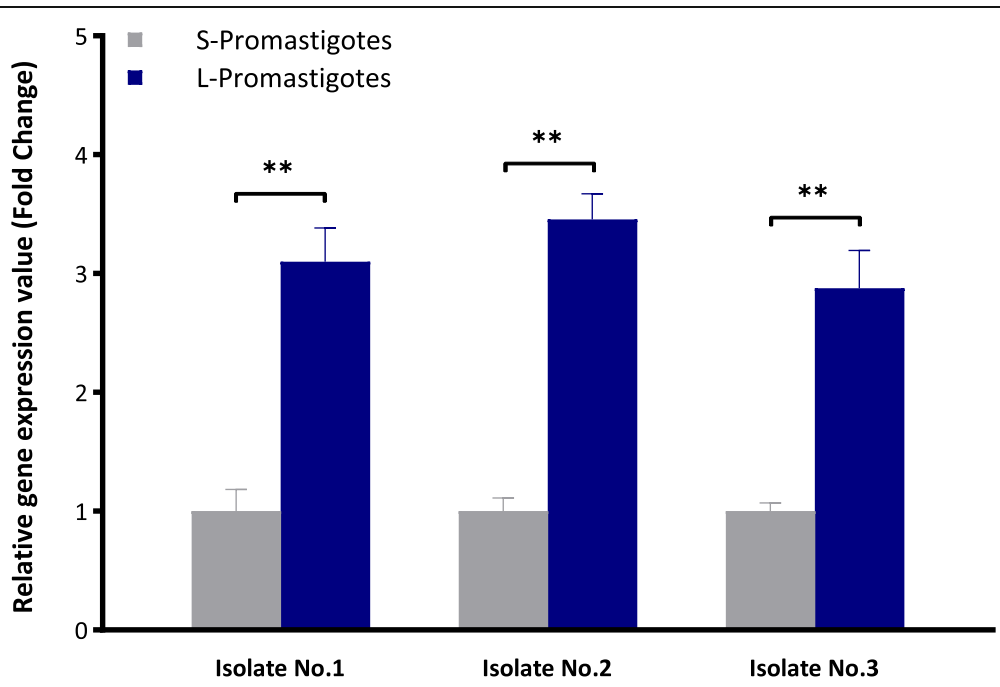

Fig. 2 Relative expression level of the centrin gene in the stationary and logarithmic-phase L. infantum isolates, using the $2^{-\Delta \Delta c t}$ method. The expression of $a$-tubulin was used to normalize the data. The values are the mean \pm SD of two independent experiments. S: stationary-phase, L: logarithmic-phase, ${ }^{* *}: p<0.01$ 


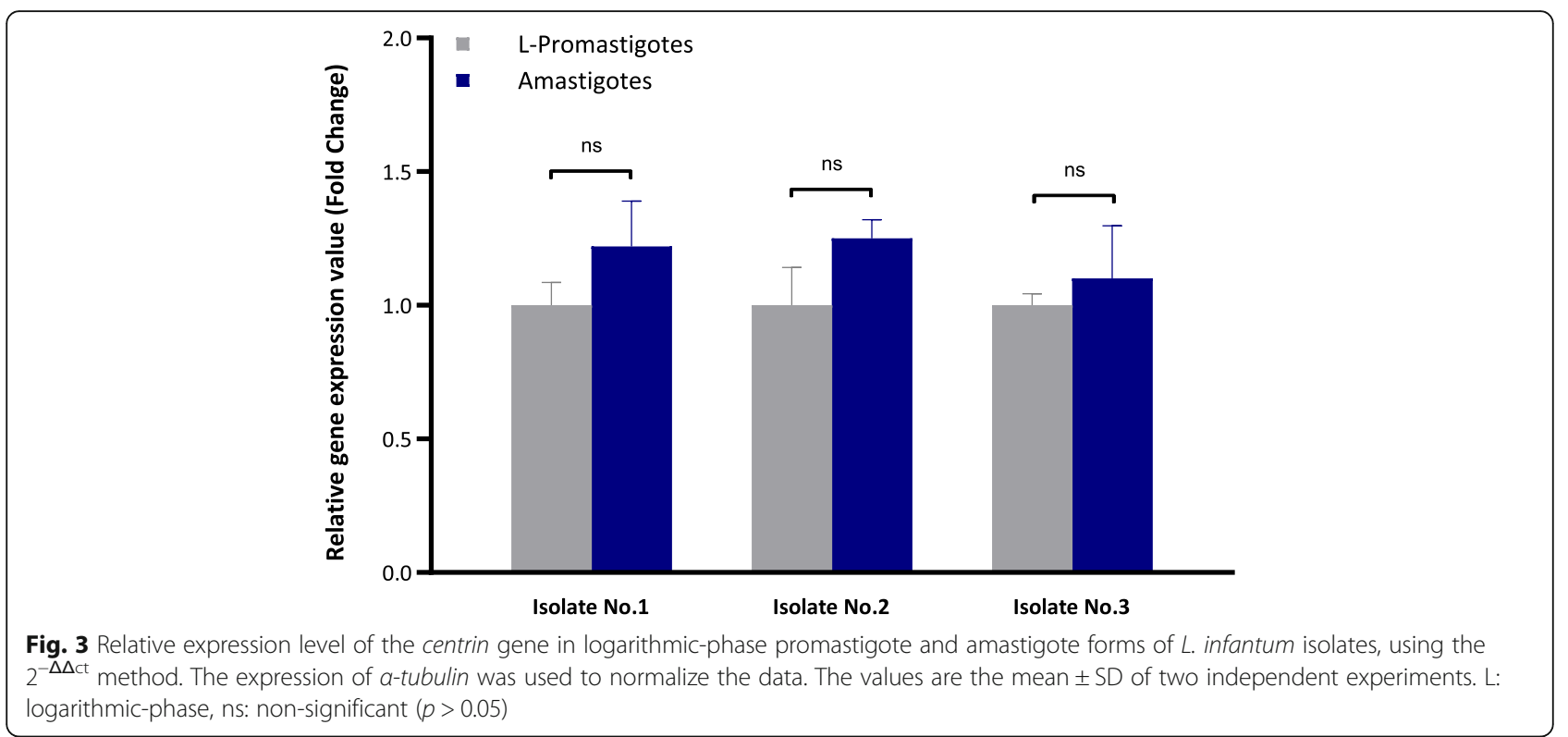

amastigote) of $L$. infantum, isolated from various endemic areas of Iran, we conducted a real-time RT-PCR.

As our results revealed, the centrin gene expression pattern had no significant difference in L. infantum isolates of various geographical areas of Iran. Our findings showed a significant up-regulation of the centrin mRNA expression in the logarithmic phase compared to the stationary phase of $L$. infantum promastigotes in all three collected isolates. The overexpression of this protein in logarithmic phase $L$. infantum parasites confirms the finding of the study carried out on Leishmania donovani (L. donovani) parasites [23]. Based on the mentioned study, Leishmania centrin protein expression was high during the exponential growth phase of the parasite in culture and significantly declined in the stationary phase. This expression pattern suggests that Leishmania centrin may have an essential role in the proliferation of the parasite. Furthermore, since stationary promastigotes compare to logarithmic ones are highly motile [24], the specified expression pattern in the current study indicates centrin protein may not have a role in the cellular movement.

Regarding the centrin gene expression level in the logarithmic phase L. infantum promastigote and amastigotes, although no significant overexpression was found, the results of this study revealed that the mRNA of $L$. infantum centrin gene is slightly more expressed in amastigotes than logarithmic promastigotes. This finding is somewhat consistent with the results of Selvapandiyan et al. [23], where they report centrin protein is equally expressed in the promastigote and amastigote forms of $L$. donovani. The results of the mentioned study have shown a defect in cell division among amastigote forms of $L$. donovani centrin gene knockout $\left(\mathrm{LdCen}^{-/-}\right)$while promastigote forms of $\mathrm{LdCen}^{-/-}$proliferate without any defect. It seems other types of proteins, such as calmodulin, $\gamma$-tubulin, and other types of centrin proteins, are responsible for basal body duplication in the promastigote forms. The lack of significant difference in the centrin expression between non-motile amastigote and promastigote forms confirms the fact that centrin has no role in parasite movement.

Leishmania parasites, especially the zoonotic species, have a complex transmission dynamic that is dependent on environmental conditions, the distribution and biology of the vector, the reservoirs involved, and the health, social, and economic aspects that affect the human host [25]. The strategies and interventions for the control of $\mathrm{VL}$, including control of vectors and reservoirs and the early detection and treatment of human cases, faced some economic and moral limitations [26]. The mentioned complex scenario for the transmission dynamics of $L$. infantum, on the other hand, makes it even more difficult to establish effective control measures and highlights the clear need for the development of an effective prophylactic vaccine against CanL [27].

Our findings, besides the results obtained by Selvapandiyan et al. $[15,23]$, showed a significant dependence of the Leishmania parasite's amastigote forms on the centrin gene activity. Centrin is a single copy gene [15], and its protein product as one of the main proteins required for duplication of the basal body and cell division could be an appropriate target for the prevention of $L$. infantum amastigotes proliferation in host cells. Defects in basal body duplication and cytokinesis in the L. infantum amastigote stage seem to be an attractive way to reach a genetically modified live attenuated vaccine against CanL. 
In this study, because of financial constraints, we just collected three $L$. infantum isolates from various endemic areas of Iran. Indeed, by evaluating more isolates, a more precise picture of the centrin expression profile could be achieved.

\section{Conclusions}

Analysis of the centrin gene expression in Iranian isolates of $L$. infantum showed this gene is more expressed in exponential than stationary phases, which highlights the potential role of centrin in the proliferation of these parasites. Understanding the role of centrin in L. infantum proliferation is a cornerstone to alter the survival of the parasite in the vertebrate host and could be a promising clue to the development of a genetically modified live attenuated vaccine against CanL.

\section{Methods}

\section{Isolates and culture}

We used three Leishmania parasites isolated from domestic dogs in endemic areas of CanL in Iran. The parasites were grown in RPMI 1640 (Gibco, Germany) culture medium supplemented with $20 \%$ heatinactivated fetal bovine serum (FBS) (Gibco, Germany), plus penicillin $(100 \mathrm{U} / \mathrm{ml})$ and streptomycin $(100 \mu \mathrm{g} /$ $\mathrm{mL}$ ) (Sigma, USA), at $\mathrm{pH} \quad 7.4$ and incubation temperature of $25^{\circ} \mathrm{C}$ [28].

\section{Molecular characterization DNA extraction}

We harvested $2 \mathrm{~mL}$ well-grown promastigotes by centrifugation $\left(800 \mathrm{~g}, 5 \mathrm{~min}\right.$ at $4^{\circ} \mathrm{C}$ ) and washed twice using sterile phosphate-buffered saline (PBS). Total DNA was extracted from the parasites using AccuPrep ${ }^{\circ}$ Genomic DNA Extraction Kit (Bioneer, Korea) according to the manufacturer's instructions and stored at $-20^{\circ} \mathrm{C}$ until the subsequent process.

\section{PCR-RFLP}

PCR-RFLP performed using the NAGT gene, which amplified using the primer set, forward (5'-TCATGACT CTTGGCCTGGTAG-3') and reverse (5'-CTCTAGCG CACTTCATCGTAG-3') [29] which amplifies a fragment of approximately 1450-60 base-pair (bp) in Leishmania parasites (Fig. 2 Lane 2). We carried out the PCR amplification in a final reaction mixture containing 25 $\mu \mathrm{L}$ including $12.5 \mu \mathrm{L} 2 \mathrm{x}$ red PCR Master Mix (Ampliqon, Denmark), $1 \mu \mathrm{L}$ of each primer (10 pmol), $1 \mu \mathrm{L}$ of the extracted DNA and $9.5 \mu \mathrm{L}$ of sterile distilled water. We applied a negative control in each run. PCR was performed in the thermal cycler (PeqLab, Germany) using the following cycling protocol: an initial denaturation step at $94^{\circ} \mathrm{C}$ for $4 \mathrm{~min}$, followed by 30 cycles of denaturation at $94^{\circ} \mathrm{C}$ for $1 \mathrm{~min}$, annealing at $53^{\circ} \mathrm{C}$ for $1 \mathrm{~min}$ and extension at $72^{\circ} \mathrm{C}$ for $1 \mathrm{~min}$, followed by a final extension step at $72^{\circ} \mathrm{C}$ for $8 \mathrm{~min}$.

Species identification was carried out using RFLP analysis. Acc1 enzyme (Thermo Scientific, USA) can provide different digestion patterns in different Leishmania species. For this purpose, we added $10 \mu \mathrm{L}$ of the amplicon, $2 \mu \mathrm{L}$ of the enzyme buffer, $1 \mu \mathrm{L}$ of the Acc1 enzyme and $17 \mu \mathrm{L}$ distilled water to the reaction. The mixture was incubated at $37^{\circ} \mathrm{C}$ for $12 \mathrm{~h}$ and then visualized on $2 \%$ agarose gel [29].

We used pre-confirmed L. infantum, Leishmania major, and Leishmania tropica species by PCR-RFLP [30], available at the School of Public Health, Tehran University of Medical Sciences as positive controls (Fig. 1 Lane 3-5, respectively).

\section{Centrin gene expression}

\section{Cell culture and amastigote isolation}

Mouse macrophage cell line RAW264.7 (ATCC number TIB-71) was obtained from the Iranian Biological Resource Center, Tehran, Iran. The macrophage cells were cultured in RPMI 1640 medium supplemented with $20 \%$ heat-inactivated FBS, penicillin $(100 \mathrm{U} / \mathrm{mL})$, and streptomycin $(100 \mu \mathrm{g} / \mathrm{mL})$ at $37^{\circ} \mathrm{C}$ in a humidified atmosphere of $5 \% \mathrm{CO}_{2}$ in $25 \mathrm{~cm}^{2}$ culture flasks (SPL, Korea). Following $72 \mathrm{~h}$ incubation (60 to $70 \%$ confluency), we washed unattached macrophages off using the prewarmed medium and incubated attached ones with the late stationary phase promastigotes (10 Leishmania per macrophage), as described by Mohtasebi et al. [31]. The culture was incubated in the same medium supplemented at $37^{\circ} \mathrm{C}$ for 4 to $6 \mathrm{~h}$ in the same condition until promastigotes were phagocyte by the macrophages. Then uninternalized parasites were washed off using pre-warmed medium.

Intracellular amastigotes were harvested and extracted from macrophages at $24 \mathrm{~h}$ and $72 \mathrm{~h}$ post-infection using a protocol as described by Decuypere et al. [32] with minor modifications. Briefly, $2 \mathrm{~mL}$ of $0.0125 \%$ sodium dodecyl sulfate (SDS)/PBS were added to the culture flask and gently agitated until macrophages lifted and started to disintegrate. After mixing, the contents of the culture flask were aspirated through a 22-gauge needle, causing further shearing of the macrophages, and transferred to a $50 \mathrm{~mL}$ tube for differential centrifugation as follows; a $30 \mathrm{~g}$ centrifugation to separate the macrophages and a $700 \mathrm{~g}$ centrifugation to obtain the amastigote pellet.

\section{RNA extraction and CDNA synthesis}

Total RNA was obtained from the $5 \times 10^{6}$ logarithmic and stationary phase promastigotes $(96 \mathrm{~h}$ and $192 \mathrm{~h}$ post-subculture, respectively) and also from the $5 \times 10^{6}$ axenic amastigotes at $24 \mathrm{~h}$ and $72 \mathrm{~h}$ post-infection of 
three L. infantum isolates, using FavorPrep ${ }^{\text {ta }}$ Total RNA Extraction Mini Kit (Favorgen, Taiwan), following the manufacturer's instructions. We performed an agarose gel electrophoresis to assess the overall quality of total RNA. The quantity of total RNA was also estimated using NanoDrop ${ }^{\text {Ty }}$ One/One ${ }^{\mathrm{C}}$ Microvolume UV-Vis Spectrophotometer (Thermo Scientific, USA). Samples having an $\mathrm{A}_{260} / \mathrm{A}_{280}$ ratio of between 1.8 and 2.0 were considered. To avoid any genomic DNA contamination, we treated the extracted RNA using DNase (Qiagen, Germany) following the manufacturer's recommendations. Total RNA was reverse transcribed from $1 \mu \mathrm{g}$ of total RNA using the cDNA Synthesis Kit (YTA, Iran) according to the manufacturer's instructions. Afterward, we evaluated the integrity of the synthesized cDNA through amplification of the $\alpha$-tubulin as a housekeeping gene using primer set, forward (5'-CAGGTGGTGT CGTCTCTGAC-3') and reverse (5'-TAGCTCGTCA GCACGAAGTG-3'), under the condition as described previously [28]. The PCR result was considered positive when a single band of $119 \mathrm{bp}$ was observed.

\section{Real-time RT-PCR}

We conducted a real-time RT-PCR assay to analyze the expression level of the centrin gene. Centrin primers were obtained using the Primer-BLAST tool [33] including forward (5'-CCGCTCTATGCACACAGACT-3') and reverse (5'- AGGTCGAAGAGCTGAAAGGC-3') which amplifies a $126 \mathrm{bp}$ fragment in the experiments. The housekeeping gene, $\alpha$-tubulin, was used as endogenous control and run along with the gene tested. RT-PCR was performed in duplicate with $20 \mu \mathrm{L}$ volumes containing $10 \mu \mathrm{L}$ RealQ Plus 2x Master Mix Green (Ampliqon, Denmark), $1 \mu \mathrm{L}$ cDNA, $1 \mu \mathrm{L}$ of each primer (10 pmol), and $7 \mu \mathrm{L}$ distilled water in a StepOne ${ }^{\mathrm{Tm}}$ Real-time PCR System (Applied Biosystems, USA). The PCR condition was as follows: initial denaturation at $95^{\circ} \mathrm{C}$ for $30 \mathrm{sec}, 40$ cycles of $10 \mathrm{sec}$ at $95^{\circ} \mathrm{C}$ and $30 \mathrm{sec}$ at $60^{\circ} \mathrm{C}$ followed by a melt curve analysis using temperature increments of $0.3^{\circ} \mathrm{C}$ every $30 \mathrm{sec}$ to ascertain amplification of the expected product. A negative control, consisting of nontemplate water instead of cDNA, was used in each run of real-time RT-PCR.

\section{Data analysis}

The relative expression of the centrin gene in the $L$. infantum isolates was estimated and normalized to the internal control gene $(\alpha$-tubulin) $)$ using the $2^{-\Delta \Delta c t}$ method [34]. The significance of differences was determined by the relative expression software tool (REST, ). All experiments conducted in duplicate and the obtained results have presented as the mean \pm standard deviations. The expression ratio results of the target gene were tested for significance by a Pair Wise Fixed Reallocation
Randomization Test $\odot$ and plotted using standard error estimation via a complex Taylor algorithm, calculated by REST. The samples with a $p$-value of $<0.05$ were considered significantly different among the groups [35].

\begin{abstract}
Abbreviations
CanL: Canine leishmaniasis; VL: Visceral leishmaniasis; PCR: Polymerase chain reaction; bp: Base-pair; RFLP: Restriction fragment length polymorphism; DNase: Deoxyribonuclease; RT: Reverse transcription; SDS: Sodium dodecyl sulfate; PBS: Phosphate-buffered saline; FBS: Fetal bovine serum; NAGT: Nacetylglucosamine-1-phosphate transferase; Acc1: Acetyl-coenzyme A carboxylase 1; CDNA: Complementary DNA; $\mathrm{LdCen}^{-1-}$ : Leishmania donovani centrin gene knockout; mRNA: Messenger RNA; BLAST: Basic local alignment search tool; REST: Relative expression software tool
\end{abstract}

\section{Acknowledgements}

We thank Dr. Elham Kazemi-Rad for her insightful suggestions during cell culture and molecular procedures.

\section{Authors' contributions}

MJAA, SE, and MM designed the study. MJAA writing the original draft. MJAA and RS carried out molecular procedures and data analysis, and SM participated in the cell culture procedure. All authors read and approved the final version of the manuscript.

\section{Funding}

This study, as a part of the PhD thesis of Mr. Mohammad Javad Abbaszadeh Afshar, was financially supported by Tehran University of Medical Sciences (Project No: 97-03-160-39686). The funding body did not play a direct role in the design of the study and collection, analysis, and interpretation of data and in writing the manuscript.

\section{Availability of data and materials}

The datasets generated and analyzed during the current study may be made available from the corresponding author on request.

Ethics approval and consent to participate

Not applicable.

\section{Consent for publication}

Not applicable.

\section{Competing interests}

The authors declare that they have no competing interests.

\section{Author details}

'Department of Medical Parasitology and Mycology, School of Public Health, Tehran University of Medical Sciences, Tehran, Iran. ${ }^{2}$ School of Pharmacy, Pacific University, Hillsboro, Oregon, USA. ${ }^{3}$ Department of Medical Parasitology and Mycology, School of Medicine, Mazandaran University of Medical Sciences, Mazandaran, Iran. ${ }^{4}$ Center for Research of Endemic Parasites of Iran (CREPI), Tehran University of Medical Sciences, Tehran, Iran.

Received: 19 July 2020 Accepted: 23 February 2021

Published online: 14 April 2021

\section{References}

1. World Health Organization. Leishmaniasis. [https://www.who.int/ leishmaniasis/burden/en/].

2. Martins VT, Duarte MC, Chávez-Fumagalli MA, Menezes-Souza D, Coelho CS, de Magalhães-Soares DF, Fernandes AP, Soto M, Tavares CA, Coelho EA. A Leishmania-specific hypothetical protein expressed in both promastigote and amastigote stages of Leishmania infantum employed for the serodiagnosis of, and as a vaccine candidate against, visceral leishmaniasis. Parasit Vectors. 2015;8(1):1-12.

3. Abbaszadeh-Afshar MJ, Mohebali M, Sharifi I, Akhoundi B, Aflatoonian MR, Bahreini MS, Mahmoudvand $\mathrm{H}$. Seroepidemiological survey of visceral leishmaniasis among nomadic tribes of Kerman province, southeastern Iran: An observational study for implication to health policy. J Biostat Epidemiol. 2015;1(3/4):105-11. 
4. Shokri A, Fakhar M, Teshnizi SH. Canine visceral leishmaniasis in Iran: A systematic review and meta-analysis. Acta trop. 2017;165:76-89.

5. Abbaszadeh-Afshar MJ, Sharifi I, Bamorovat M, Mohebali M, Bahreini MS, Naderi A. Canine visceral leishmaniasis; A seroepidemiological survey in Jiroft district, southern Kerman province, southeastern Iran in 2015. Iran J Parasitol. 2018;13(1):67-71.

6. Moreno J, Alvar J. Canine leishmaniasis: epidemiological risk and the experimental model. Trends parasitol. 2002;18(9):399-405.

7. Ismail N, Kaul A, Bhattacharya P, Gannavaram S, Nakhasi HL. Immunization with live attenuated Leishmania donovani centrin ${ }^{-1}$ parasites is efficacious in asymptomatic infection. Front Immunol. 2017;8:1788.

8. Selvapandiyan A, Dey R, Nylen S, Duncan R, Sacks D, Nakhasi HL. Intracellular replication-deficient Leishmania donovani induces long lasting protective immunity against visceral leishmaniasis. J Immunol. 2009;183(3): 1813-20.

9. Bifeld $\mathrm{E}, \mathrm{Clos}$ J. The genetics of Leishmania virulence. Med Microbiol Immunol. 2015;204(6):619-34.

10. Joshi M, Dwyer DM, Nakhasi HL. Cloning and characterization of differentially expressed genes from in vitro-grown 'amastigotes' of Leishmania donovani. Mol Biochem parasitol. 1993;58(2):345-54.

11. Alcolea PJ, Alonso A, Degayón MA, Moreno-Paz M, Jiménez M, Molina R, Larraga $V$. In vitro infectivity and differential gene expression of Leishmania infantum metacyclic promastigotes: negative selection with peanut agglutinin in culture versus isolation from the stomodeal valve of Phlebotomus perniciosus. BMC Genomics. 2016;17:375.

12. Dey R, Meneses C, Salotra P, Kamhawi S, Nakhasi HL, Duncan R. Characterization of a Leishmania stage-specific mitochondrial membrane protein that enhances the activity of cytochrome coxidase and its role in virulence. Mol Microbiol. 2010;77(2):399-414.

13. Grimaldi G Jr, Teva A, Dos-Santos CB, Santos FN, Pinto ID, Fux B, Leite GR, Falqueto $A$. Field trial of efficacy of the Leish-tec ${ }^{\circledast}$ vaccine against canine leishmaniasis caused by Leishmania infantum in an endemic area with high transmission rates. PloS one. 2017;12(9):e0185438.

14. Pogue GP, Koul S, Lee NS, Dwyer DM, Nakhasi HL. Identification of intra-and interspecific Leishmania genetic polymorphisms by arbitrary primed polymerase chain reactions and use of polymorphic DNA to identify differentially regulated genes. J Parasitol Res. 1995;81(4):282-90.

15. Selvapandiyan A, Duncan R, Debrabant A, Bertholet S, Sreenivas G, Neg NS, Salotra P, Nakhasi HL. Expression of a mutant form of Leishmania donovani centrin reduces the growth of the parasite. J Biol Chem. 2001; 276(46):43253-61.

16. Wiech H, Geier BM, Paschke T, Spang A, Grein K, Steinkötter J, Melkonian M, Schiebel E. Characterization of green alga, yeast, and human centrins specific subdomain features determine functional diversity. J Biol Chem. 1996;271(37):22453-61.

17. Baum P, Furlong C, Byers B. Yeast gene required for spindle pole body duplication: homology of its product with $\mathrm{Ca}^{2+}$-binding proteins. Proc Natl Acad Sci. 1986;83(15):5512-6.

18. Paoletti A, Bordes N, Haddad R, Schwartz CL, Chang F, Bornens M. Fission yeast cdc31p is a component of the half-bridge and controls SPB duplication. Mol Biol Cell. 2003;14(7):2793-808.

19. Salisbury JL, Suino KM, Busby R, Springett M. Centrin-2 is required for centriole duplication in mammalian cells. Curr Biol. 2002;12(15):1287-92.

20. Koblenz B, Schoppmeier J, Grunow A, Lechtreck K-F. Centrin deficiency in Chlamydomonas causes defects in basal body replication, segregation and maturation. J Cell Sci. 2003;116(13):2635-46.

21. Selvapandiyan A, Kumar P, Morris JC, Salisbury JL, Wang CC, Nakhasi HL. Centrin 1 is required for organelle segregation and cytokinesis in Trypanosoma brucei. Mol Biol Cell. 2007;18(9):3290-301.

22. Mahajan B, Selvapandiyan A, Gerald NJ, Majam V, Zheng H, Wickramarachchi T, Tiwari J, Fujioka H, Moch JK, Kumar N. Centrins, cell cycle regulation proteins in human malaria parasite Plasmodium falciparum. J Biol Chem. 2008;283(46):31871-83.

23. Selvapandiyan A, Debrabant A, Duncan R, Muller J, Salotra P, Sreenivas G, Salisbury JL, Nakhasi HL. Centrin gene disruption impairs stage-specific basal body duplication and cell cycle progression in Leishmania. J Biol Chem. 2004;279(24):25703-10.

24. Inbar E, Hughitt VK, Dillon LA, Ghosh K, El-Sayed NM, Sacks DL. The transcriptome of Leishmania major developmental stages in their natural sandfly vector. mBio 2017, 8(2).
25. Burza S, Croft SL, Boelaert M. Leishmaniasis. The Lancet. 2018;392(10151): 951-70.

26. Ibarra-Meneses AV, Moreno J, Carrillo E. New strategies and biomarkers for the control of visceral leishmaniasis. Trends Parasitol. 2020;36(1):29-38.

27. Viana KF, Fiuza JA, Gannavaram S, Dey R, Selvapandiyan A, Bartholomeu DC, da Silveira-Lemos D, Bueno LL, Dutra WO, Fujiwara RT. Application of rapid in vitro co-culture system of macrophages and T-cell subsets to assess the immunogenicity of dogs vaccinated with live attenuated Leishmania donovani centrin deleted parasites ( $\left(\mathrm{LCen}^{-1}\right)$. Parasit Vectors. 2016;9(1):250

28. Hajjaran H, Kazemi-Rad E, Mohebali M, Oshaghi MA, Khadem-Erfan MB, Hajaliloo E, Reisi Nafchi H, Raoofian R. Expression analysis of activated protein kinase $C$ gene (LACK 1) in antimony sensitive and resistant Leishmania tropica clinical isolates using real-time RT-PCR. Int J Dermatol. 2016;55(9):1020-6.

29. Saberi R, Moin-Vaziri V, Hajjaran H, Niyyati M, Taghipour N, Kheirandish F, Abadi A. Identification of Leishmania species using $\mathrm{N}$-acetylglucosamine-1phosphate transferase gene in a zoonotic cutaneous leishmaniasis focus of Iran. J Vector Borne Dis. 2018;55(1):14.

30. Teimouri A, Mohebali M, Kazemirad E, Hajjaran H. Molecular identification of agents of human cutaneous leishmaniasis and canine visceral leishmaniasis in different areas of Iran using internal transcribed spacer 1 PCR-RFLP. J Arthropod Borne Dis. 2018;12(2):162.

31. Mohtasebi S, Mohebali M, Elikaee S, Akhoundi B, Foroushani AR, Teimouri A, Yarizadeh $\mathrm{H}$. In vitro and in vivo anti-parasitic activity of biogenic antimony sulfide nanoparticles on Leishmania major (MRHO/IR/75/ER). J Parasitol Res. 2019:118(9):2669-78.

32. Decuypere S, Vanaerschot M, Rijal S, Yardley V, Maes L, De Doncker S, Chappuis F, Dujardin J-C. Gene expression profiling of Leishmania (Leishmania) donovani: overcoming technical variation and exploiting biological variation. Parasitology. 2008;135(2):183-94.

33. Primer-BLAST. [https://pubmed.ncbi.nlm.nih.gov/tools/primer-blast/]

34. Livak K, Schmittgen T. Analysis of relative gene expression data using realtime quantitative PCR and the 2 (-Delta Delta C (T)) Method. Methods 2001, 25(4):402-408

35. Pfaffl MW, Horgan GW, Dempfle L. Relative expression software tool (RESTC) for group-wise comparison and statistical analysis of relative expression results in real-time PCR. Nucleic Acids Res. 2002;30(9):e36-6.

\section{Publisher's Note}

Springer Nature remains neutral with regard to jurisdictional claims in published maps and institutional affiliations.

Ready to submit your research? Choose BMC and benefit from:

- fast, convenient online submission

- thorough peer review by experienced researchers in your field

- rapid publication on acceptance

- support for research data, including large and complex data types

- gold Open Access which fosters wider collaboration and increased citations

- maximum visibility for your research: over $100 \mathrm{M}$ website views per year

At $\mathrm{BMC}$, research is always in progress.

Learn more biomedcentral.com/submission 